\title{
Это не инструмент только для «хорошей погоды»: необходимость переосмыслить укрепление военного доверия в Европе
}

\author{
Бенджамин Шаллер ${ }^{*}$
}

\section{Аннотация}

Нынешний кризис доверия в Европе, несомненно, повлиял на отношения между Россией и Западом в области обороны и безопасности. На этом фоне явно выделяются относительно конструктивные и хорошо налаженные рабочие отношения, которые и в настоящее время поддерживаются между структурами, занимающимися вопросами контроля над вооружениями. В этой связи встает вопрос о целесообразности переосмысления роли мер укрепления доверия и безопасности (МДБ) в укреплении доверия между государствами-участниками ОБСЕ. В статье предлагаются новые аналитические рамки для понимания того, как МДБ способствуют повышению уровня доверия между структурами, занимающимися вопросами контроля над вооружениями, новые подходы к тому, как можно повысить их позитивное воздействие на отношения в области обороны и безопасности в условиях политической напряженности и недоверия. Главный вывод заключается в том, что МДБ в принципе вполне функциональны, но эффект, который достигается в процессе их применения, не влияет на уровень принятия решений в области обороны и безопасности. В условиях современного кризиса в области европейской безопасности следует сосредоточиться на многосторонних формах проверки, укреплении контактов между военными, найти способы усилить позитивный эффект применения МДБ, не ограничиваясь относительно небольшим сообществом специалистов по контролю над вооружениями, и инвестировать в целенаправленное укрепление доверия на более высоком политическом и военном уровнях.

\section{Ключевые слова}

ОБСЕ, военная безопасность, меры укрепления доверия и безопасности, контроль над вооружениями

Для цитирования этой публикации: Шаллер Б. Это не инструмент только для «хорошей погоды»: необходимость переосмыслить укрепление военного доверия в Европе // ОБСЕ Insights 7. - Баден-Баден: Номос, 2021. URL: https://doi.org/10.5771/9783748921264-07

* Бенджамин Шаллер, доктор наук, Университет Тромсё - Арктический университет Норвегии, benjamin.schaller@uit.no 


\section{Введение 209}

Прошло больше шести лет с начала конфликта в Украине и вокруг нее, а Европа еще не преодолела один из самых глубоких кризисов со времен окончания «холодной войны». В то время как кризис доверия в отношениях между Россией и Западом продолжает углубляться, сформированные в ОБСЕ режимы контроля над обычными вооружениями и укрепления доверия, когда-то занимавшие центральное место в преодолении раскола между Востоком и Западом, по всей видимости, стали еще одной сферой политического и стратегического противостояния России и Запада. В 2016 г. Россия заблокировала обновление Венского документа о мерах укрепления доверия и безопасности (МДБ), ссылаясь на то, что линия НАТО «на военное сдерживание России, конкретные шаги альянса в военной области исключают возможность достижения договоренностей по мерам укрепления доверия» ${ }^{210}$. В 2020 году президент Дональд Трамп объявил, что Соединенные Штаты выйдут из Договора по открытому небу из-за его неоднократных нарушений Россией 211 . В условиях, когда серьезные усилия по модернизации Венского документа блокированы в течение многих лет, а в политической повестке дня доминируют взаимные обвинения в нарушении обязательств и споры по поводу интерпретации результатов проверок 212 , высказывались сомнения в возможности укрепления доверия в военной области в принципе. Существующие же МДБ стали восприниматься как инструменты, применимые только при «хорошей погоде», в и без того благоприятных политических условиях.

В статье утверждается, что этот негативный прогноз не отражает нынешнее положение дел в области укрепления доверия в военной сфере в Европе. Помимо того, что осуществлявшаяся в рамках Венского документа и Договора по открытому небу деятельность позволила получить важную информацию в начале кризиса в Украине и вокруг нее ${ }^{213}$, относительно хорошие рабочие отношения, которые установились между структурами, занимающимися вопросами контроля над вооружениями, выделяются в лучшую сторону на фоне того негативного воздействия, которое взаимные обвинения и напряженность оказали на политические и военные отношения на высоком уровне между Россией и Западом ${ }^{214}$. Хотя фактом сохранения позитивных рабочих отношений можно было бы пренебречь как частным примером, не оказывающим заметное влияние на общую обстановку, мы полагаем, целесообразным разобраться в причинах кажущегося несопоставимым опыта на политическом и исполнительном уровнях.

В статье предлагается переосмыслить подходы и роль МДБ в укреплении доверия между государствами-участниками ОБСЕ. Традиционно основное внимание уделялось роли и влиянию МДБ на более высоком политическом и военном уровнях. Мы же полагаем, что знание того, как МДБ способствуют повышению доверия на рабочем уровне между структурами, занимающимися контролем над вооружениями, позволит понять и то, как можно усилить более широкий эффект от примене- 
ния существующих режимов МДБ в условиях политической напряженности и недоверия.

С этой целью в статье сначала будут рассмотрены как положительные стороны, так и недостатки традиционного подхода, связывающего укрепление доверия в военной области с повышением транспарентности и контролем. Во-вторых, опираясь на результаты диссертационного исследования автора по вопросам доверия в сфере оборонной политики и политики безопасности, в статье предлагается новый подход к пониманию того, как МДБ способствуют повышению доверия между структурами, которые занимаются вопросами контроля над вооружениями. Статья завершается соображениями о том, как полученные выводы могут быть использованы в рамках существующих режимов МДБ, с тем чтобы укрепление военного доверия могло оказать более всестороннее воздействие на общие отношения в области обороны и безопасности между государствами-участниками ОБСЕ.

\section{Доверяй, но проверяй: Недостатки традиционного подхода к МДБ}

Традиционно укрепление доверия в сфере обороны и безопасности часто сводилось к простой парадигме: «Доверяй, но проверяй». Эта русская пословица, популяризированная бывшим президентом США Рональдом Рейганом во время американосоветских переговоров по контролю над вооружениями в 1980 -е годы ${ }^{215}$, прекрасно отражает сложившееся понимание роли мер контроля над вооружениями и укрепления доверия в сфере обороны и безопасности. Считается, что благодаря сочетанию повышенной транспарентности и предсказуемости в отношении военных сил, вооружений и деятельности с тщательным и интрузивным режимом проверки контроль над вооружениями и МДБ вносят вклад в повышение доверия между государствами ${ }^{216}$.

Проблема, однако, заключается в том, что государства могут иметь существенные мотивы для искажения или сокрытия соответствующей информации, например, с целью получения стратегического преимущества ${ }^{217}$. Эта проблема, по-видимому, характерна особенно для ситуаций, когда доверие утрачено, а государства имеют сильные стимулы для дискредитации результатов проверок, например, для сокрытия случаев несоблюдения обязательств или для усиления дипломатического давления и изоляции политических оппонентов на международной арене. К этому следует добавить, что в отличие от большинства договоров по разоружению и контролю над вооружениями МДБ обычно не предполагают создание режима тщательной и интрузивной проверки. Так, если юридически обязывающий Договор об обычных вооруженных силах в Европе содержит положения о комплексной и интрузивной проверке выполнения обязательств в области разоружения и контроля над вооружениями ${ }^{218}$, то политически обязывающий Венский документ о мерах укрепления доверия и безопасности предусматривает лишь ограниченное число возможностей для 
менее интрузивной проверки. Он допускает проведение не более трех инспекций и одного посещения по оценке на каждые шестьдесят частей, сведения о которых включены в ежегодный обмен информацией ${ }^{219}$. В случае России это составляет максимум три инспекции и два посещения по оценке в год ${ }^{220}$. Кроме того, пороговые значения, начиная с которых приглашение наблюдателей на крупномасштабные мероприятия военной деятельности является обязательным, слишком высоки для современных военных реалий, в то время как государства-участники ОБСЕ, прежде всего Россия, нашли креативные способы избежать обязательного наблюдения за их военными учениями 221 .

Поэтому неудивительно, что МДБ зачастую подвергаются серьезной критике в периоды нарастания политической напряженности и недоверия и что в центре политических споров о необходимости их модернизации, как правило, стоят вопросы увеличения числа инспекций и посещений по оценке, а также - снижения пороговых значений для уведомления и наблюдения за определенными видами военной деятельности ${ }^{222}$. Обсуждение модернизации МДБ, несомненно, имеет большое значение, но оно не должно ограничиваться вопросами повышения транспарентности и проверки. Хотя транспарентность и проверка играют важную роль в уменьшении недоверия путем сдерживания (или, по крайней мере, обнаружения) возможных нарушений со стороны государств на раннем этапе, среди ученых широко распространено понимание того, что никакая система проверки - какой бы интрузивной она ни была - не обеспечит абсолютную уверенность в фактическом соблюдении другим государством его обязательств ${ }^{223}$. Споры, ведущиеся по поводу предполагаемых случаев несоблюдения и выводов, сделанных по итогам проверки, свидетельствуют о том, что в отсутствие доверия мероприятия по проверке могут даже привести к обратному результату: усилить взаимное негативное восприятие и недоверие в сфере обороны и безопасности. Иными словами, можно утверждать, что для того, чтобы развеять имеющиеся сомнения, проверка предполагает по меньшей мере минимальный уровень доверия с обеих сторон ${ }^{224}$.

Эта очевидная дилемма порождает трудный вопрос о том, как установить первоначальный уровень доверия в периоды обострения политической напряженности и недоверия. Для ответа на него и для понимания того, каким образом МДБ способствуют укреплению доверия в отношениях между структурами, занимающимися вопросами контроля над вооружениями, рассмотрим практику их применения.

\section{Укрепление доверия в военной сфере в процессе применения МДБ}

Чтобы понять, как МДБ способствуют установлению хороших рабочих отношений и укреплению доверия в процессе их осуществления, мы предлагаем опереться на сформулированные Гордоном Олпортом условия, необходимые для поддержания конструктивных межгрупповых контактов. В основу для понимания и анализа эф- 
фекта МДБ с точки зрения укрепления доверия между участвующими в их осуществлении офицерами мы положим его первоначальную гипотезу контакта 225 . В своей работе Олпорт предположил, что межгрупповые контакты, которые (а) осуществляются в условиях равного статуса, (б) преследуют общие цели, (в) сосредоточены на сотрудничестве и (г) получают активную поддержку со стороны влаcmeй, помогают уменьшить предрассудки и снизить напряженность в отношениях между группами большинства и меньшинства в обществе ${ }^{226}$. Позднее этот перечень был дополнен еще одним условием, в соответствии с которым межгрупповые контакты должны также д) способствовать формированию межгрупповых дружеских отношений 227.

Основываясь на интервью с офицерами, участвующими в практической деятельности по осуществлению контроля над вооружениями, проведенными в ходе нашего диссертационного исследования по вопросам доверия и недоверия в сфере оборонной политики и политики безопасности 228 , мы можем утверждать, что сформулированные Олпортом условия помогают понять, как МДБ способствуют укреплению доверия на уровне исполнителей.

Во-первых, говоря о равном статусе, интересно, что общим для большинства опрошенных офицеров является не просто их прошлая служба в вооруженных силах, но и то, что они ощущают себя частью более широкого «сообщества по контролю над вооружениями», в котором офицеры, как правило, имеют общее понимание того, как различные документы и договоры должны осуществляться на практике 229 . Это общее понимание проявляется еще сильнее, если офицеры относятся к одному и тому же командному звену (тактическому, оперативному или стратегическому), к одному и тому же роду войск (армия, военно-воздушные силы, военно-морской флот) или если их страны в той или иной форме сотрудничают в сфере обороны 230 .

Во-вторых, когда речь идет о достижении общих ияелей, то основные задачи инспектирующей и принимающей группы, на первый взгляд, существенно различаются. Если инспектирующая группа должна проверить соблюдение инспектируемым государством его обязательств, принимающая группа в первую очередь озабочена обеспечением сложного баланса между соблюдением положений соответствующих договоренностей и тщательным регулированием и, там где это необходимо, ограничением доступа инспектирующей группы к чувствительной военной информации. В то же время обе группы осознают, что сегодняшняя принимающая группа завтра будет инспектирующей. Это обеспечивает высокий уровень взаимозависимости и помогает объяснить обычно дружественную, профессиональную и конструктивную атмосферу в ходе осуществления мер укрепления доверия и безопасности ${ }^{231}$.

В-третьих, взаимозависимость обеспечивает высокий уровень сотрудничества в ходе реализации МДБ. Это сотрудничество и, в частности, связанное с ним личное взаимодействие между инспектирующей и принимающей группами, рассматривается участвующими в этой деятельности офицерами как один из важнейших элементов формирования доверия на уровне исполнителей. Данный эффект ощущается 
еще сильнее в тех случаях, когда сотрудничество сосредоточено на решении четко определенной общей задачи, такой как проведение совместных наблюдательных полетов в соответствии с Договором по открытому небу или проверка определенной военной техники в ходе посещения по оценке в соответствии с Венским документом $^{232}$. По словам одного из офицеров: «Вы должны уметь считать. Не потому что подсчет обязательно важен, а потому что вы должны [...] работать над чем-то [вместе]» 233 .

В-четвертых, какими бы позитивными и доверительными ни были отношения между участвующими в осуществлении МДБ офицерами, политическое руководство и поддержка со стороны властей, по всей вероятности, останутся решающим фактором в поддержании режимов МДБ. Поскольку большинство правительств заинтересованы в сохранении репутации своих стран как соблюдающих обязательства по международным документам и договорам, участвующие в проверках офицеры могут по крайней мере рассчитывать на общую поддержку их работы. В то же время серьезная напряженность на более высоком политическом и военном уровне, будь то в связи с несоблюдением существующих или обсуждением новых мер контроля над вооружениями и МДБ, регулярно приводила к серьезным сбоям в реализации соглашений о контроле над вооружениями и МДБ. Это может выражаться в ограничении доступа и снижении уровня сотрудничества в ходе осуществления мероприятий по проверке 234 . В худшем случае политическая напряженность может даже привести к полному застою, как это произошло в неурегулированном политическом споре между Россией и Грузией, который привел к полному прекращению всех наблюдательных полетов в соответствии с Договором по открытому небу в 2018 году 235 . Однако участвующие в реализации мер по контролю над вооружениями офицеры отмечают, что в то время как политическая напряженность сказывается на работе политизированных, официальных форумов, комитетов и органов ОБСЕ, общая атмосфера в ходе посещений по оценке, инспекций и наблюдения остается «дружественной» и «профессиональной» ${ }^{236}$. Некоторые участники проверок подчеркивают, что они просто не обсуждают сложные политические вопросы в ходе своего взаимодействия с офицерами из других стран, и сосредоточивают внимание на военно-технических аспектах своей работы ${ }^{237}$.

Наконец, судя по всему во многом благодаря профессиональным встречам и просто общению во время ужинов, приемов, поездок на автобусе или джипе МДБ создают благоприятные условия для развития профессиональных межсрупповых дружеских отношений. Этому способствует тот факт, что международное сообщество, занимающееся вопросами контроля над вооружениями, относительно невелико, и большинство участвующих в этой деятельности офицеров реже меняют место прохождения службы, чем их коллеги в вооруженных силах. Это позволяет устанавливать более личные отношения и связи, которые можно использовать для решения более мелких проблем, не доводя их до обсуждения на более высоком уровне политического и военного руководства ${ }^{238}$. 
Таким образом, рассмотрение через призму изложенных выше необходимых для поддержания конструктивных межгрупповых контактов условий расширяет наше понимание того, как МДБ способствуют повышению доверия на уровне исполнителей, и открывает новые интересные перспективы. Тем не менее, поскольку многие из перечисленных эффектов ограничиваются относительно небольшой группой офицеров, занимающихся вопросами контроля над вооружениями, необходимо разобраться, как такое понимание функционирования МДБ может способствовать более широкому укреплению доверия.

\section{Переосмысление укрепления военного доверия в Европе}

На протяжении вот уже нескольких лет продолжаются безуспешные попытки сохранить в Европе предполагаемую стабилизирующую роль мер по укреплению доверия в военной области в условиях нарастания напряженности и недоверия между государствами-участниками ОБСЕ. Хотя лучшее понимание того, как МДБ способствуют укреплению доверия между участвующими в их осуществлении офицерами, не разрешит глубокие политические противоречия, которые долгое время доминировали в обсуждении современного состоянии и будущего контроля над вооружениями и МДБ в Европе, оно позволяет посмотреть на проблему по-новому и показать как неадекватность интерпретации МДБ как «инструментов хорошей погоды», так и недостатки их узкого понимания по принципу «доверяй, но проверяй».

Исходя из того, какие условия способствуют укреплению доверия на уровне исполнителей, можно выделить четыре основные области, важные для усиления эффекта от применения МДБ в периоды напряженности. Во-первых, несмотря на неадекватность подхода, сводящего дискуссию к принципу «доверяй, но проверяй», государствам-участникам важно попытаться сократить масштабы их разногласий относительно интерпретации результатов проверки. Хотя увеличение проверочных квот и снижение пороговых значений для наблюдения за военной деятельностью, безусловно, важны для этого, следует уделять больше внимания многосторонним формам проверки. Их использование возможно путем более частого формирования многонациональных верификационных групп или изучения возможностей расширения роли ОБСЕ в осуществлении проверок ${ }^{239}$. Многосторонний подход имеет ряд преимуществ по сравнению с нынешними процедурами. С одной стороны, он позволяет вынести обсуждение результатов проверки за рамки более конфликтных двусторонних отношений и обеспечить более объективную информацию. Данное обстоятельство представляется особенно важным в кризисных ситуациях, когда необходимы оперативные и адекватные меры реагирования ${ }^{240}$. С другой стороны, многосторонняя проверка дает дополнительные эффекты в плане укрепления доверия, поскольку входящие в состав многонациональных групп инспекторы, как правило, 
имеют равный статус и еще более активно сотрудничают в достижении общей цели - проверки соблюдения ${ }^{241}$.

Во-вторых, поскольку меры по проверке предполагают хотя бы минимальный уровень доверия, а их осуществление зачастую осложняется в условиях нарастания напряженности в отношениях между государствами, следует прилагать еще больше усилий для сохранения, а в идеале - для укрепления конструктивных рабочих отношений на уровне исполнителей. Анализ, проведенный в предыдущем разделе, позволяет сделать вывод о том, что при осуществлении МДБ не следует ограничиваться только проверкой соблюдения. Главная цель должна заключаться в увеличении числа личных встреч и объема взаимодействия между структурами, занимающимися вопросами контроля над вооружениями. В идеале такое взаимодействие должно происходить в интересах решения четко определенной и ограниченной военной задачи. Это способствует повышению уровня взаимозависимости и позволяет сотрудничающим сторонам избегать сложных и противоречивых политических дискуссий. Как уже упоминалось, хорошим примером такого рода взаимодействия в целях укрепления доверия является Договор по открытому небу, который сводит вместе офицеров ВВС стран, не являющихся союзниками, для проведения совместных наблюдательных полетов. Аналогичного эффекта можно было бы добиться на основе различных форм контактов между военными, как это предусмотрено в главе IV Венского документа, включая посещения и обмены между офицерами и воинскими подразделениями, участие в совместных семинарах, подготовке кадров и языковых курсах, а также проведение совместных военных учений и учебных мероприятий 242 . Хотя такие меры предусмотрены многими режимами МДБ и осуществляются различными государствами-участниками ОБСЕ, следует рассмотреть возможность их более частого и целенаправленного использования в периоды политической напряженности и недоверия.

В-третьих, поскольку эффект от применения МДБ в настоящее время в основном ограничивается небольшой группой специалистов-практиков, следует изучить возможности расширения круга участвующих в осуществлении МДБ офицеров различных родов войск и уровней командования в вооруженных силах. Для этого, несмотря на то, что освоение сложных и имеющих технический характер соглашений о контроле над вооружениями, а также налаживание конструктивных межличностных отношений требуют времени и опыта, стоит рассмотреть вопрос о переводе (по крайней мере некоторых) офицеров, занимающихся вопросами контроля над вооружениями, на более длительные, но регулярные циклы ротации (например, каждые пять-десять лет). Для сохранения этих сотрудников как узкоспециализированных экспертов по конкретным вопросам ротация могла бы происходить, например, между структурами, осуществляющими деятельность по проверке выполнения соглашений о контроле над вооружениями и МДБ, подразделениями, занимающимися концептуальными вопросами, и отделами министерств, в компетенцию которых входят вопросы МДБ и контроля над вооружениями. На национальном уровне повышению 
эффекта от применения МДБ способствовало бы регулярное включение офицеров из различных структур вооруженных сил, а также представителей профильных отделов министерств обороны и иностранных дел в группы, принимающие иностранных инспекторов, в собственные инспекционные группы и группы наблюдателей. Некоторые небольшие страны, такие как Норвегия и Швеция, привлекают к этой деятельности внештатных сотрудников (главным образом по причине ограниченной численности персонала) ${ }^{243}$. Использование данного опыта могло бы способствовать целенаправленному расширению эффекта от применения МДБ, включая в этот процесс более широкий круг лиц, занимающихся самыми разными вопросами политики в области обороны и безопасности.

Наконец, при всей необходимости укреплять МДБ и поддерживать нормальные отношения между структурами, занимающимися вопросами контроля над вооружениями, не следует переоценивать их роль в преодолении современной политической и военной напряженности в отношениях между Россией и Западом. Поскольку корни нынешнего кризиса уходят гораздо глубже, обеим сторонам следует предпринять целенаправленные усилия по укреплению доверия на более высоком политическом и военном уровне. Исходя из опыта практического применения МДБ, такие усилия должны быть сосредоточены на вопросах, представляющих взаимный интерес, создавать высокий уровень взаимозависимости и обеспечивать, чтобы взаимодействие происходило в условиях равного статуса. Примерами форматов, которые в значительной степени отвечают условиям для установления конструктивных межгрупповых контактов, являются семинары высокого уровня по военным доктринам $^{244}$ и ознакомительные поездки в целях повышения уровня знаний о национальных процедурах оборонного планирования ${ }^{245}$, предусмотренные Венским документом, а также соглашения о поддержании «горячих» линий связи и двусторонние встречи на более высоком политическом и военном уровне, как, например, недавно возобновившиеся заседания Российско-германской рабочей группы высокого уровня по вопросам политики безопасности ${ }^{246}$ и консультации между норвежским и российским министерствами обороны ${ }^{247}$. Хотя такие переговоры не могут гарантировать быстрое восстановление нормальных отношений (или «бизнеса как обычно»), они создают площадки и возможности для откровенного и открытого обмена мнениями по главным вопросам, порождающим напряженность в отношениях России с Западом, таким как конфликты в Украине и в Сирии, ядерное разоружение и контроль над вооружениями, иранская ядерная сделка, борьба с терроризмом ${ }^{248}$. На многостороннем уровне аналогичные обсуждения могли бы проходить в рамках «структурированного диалога» на площадке ОБСЕ, который дает возможность для неформального обмена мнениями между официальными представителями государств и экспертами по текущим и будущим вызовам и рискам для безопасности в регионе ОБСЕ (включая контроль над вооружениями, восприятие угроз, военные учения и мероприятия) $)^{249}$, или в рамках Совета Россия-НАТО 250. 
Переосмысление того, как МДБ способствуют росту доверия в сфере оборонной политики и политики безопасности, открывает новые возможности для повышения их эффективности и укрепления доверия в условиях политической напряженности и недоверия. Помимо рассмотрения возможности расширения практики проведения многосторонних проверок и уменьшения различий в интерпретации их результатов в рамках существующих режимов это позволило бы по достоинству оценить и укрепить потенциал МДБ по установлению более доверительных отношений на уровне исполнителей и сформировать механизмы, способствующие преодолению политических и стратегических противоречий, которые в настоящее время определяют отношения между Россией и Западом в области обороны и безопасности.

\section{Заключительные замечания и рекомендации}

На фоне взаимных обвинений в нарушении соглашений по контролю над вооружениями и глубокого кризиса доверия в отношениях между Россией и Западом МДБ все чаще расценивают как инструменты, применимые только в условиях «хорошей погоды». Как мы постарались показать в статье, такая негативная оценка не соответствует положению дел в сфере укрепления доверия в военной области в Европе, для которой характерны относительно хорошо функционирующие рабочие отношения между структурами, занимающимися контролем над вооружениями. Другими словами, проблема не в том, что МДБ дисфункциональны, а в том, что они, как правило, не адресованы старшим должностным лицам, принимающим решения, касающиеся вопросов обороны и безопасности. Поэтому положительный эффект от их применения ограничивается небольшой группой экспертов по контролю над вооружениями.

Конструктивные отношения между структурами, занимающимися контролем над вооружениями, сами по себе не выведут отношения между Россией и Западом в сфере оборонной политики и политики безопасности из современного глубокого кризиса доверия. В статье показано, что на основе социально-психологической концепции развития конструктивных межгрупповых контактов можно составить лучшее представление о том, как МДБ способствуют укреплению доверия и взаимодействию между офицерами, участвующими в деятельность по обеспечению контроля над вооружениями. Это позволяет по-новому оценить возможности повышения эффекта от применения МДБ в условиях политической напряженности и недоверия. Исходя из положения о том, что конструктивное взаимодействие в идеале а) должно происходить в условиях равного cmamyca, б) преследовать общие цели, в) быть сосредоточено на сотрудничестве, г) поддерживаться властями и д) способствовать установлению профессиональных межгрупповых дружеских отношений, в ходе дальнейшего обсуждения МДБ следует уделять больше внимания следующим вопросам и приоритетным областям: 
- Многосторонняя проверка. Хотя усиление проверки и сокращение различий в интерпретации полученных результатов путем увеличения числа проверок, понижения порогов для обязательного наблюдения и более строгого режима верификации, безусловно, важны, следует уделять больше внимания многосторонним механизмам проверки, которые не только обеспечивают получение более объективной информации во время кризиса, но и дают дополнительный эффект в плане укрепления доверия между членами группы. Многосторонняя проверка могла бы осуществляться путем более частого включения инспекторов из других государств в состав национальных инспекционных групп или путем расширения роли ОБСЕ в осуществлении проверок.

- Укрепление контактов между военными. Поскольку проверка предполагает хотя бы минимальный уровень доверия для реализации ее стабилизирующего и укрепляющего доверие потенциала, важно, чтобы правительства еще больше инвестировали в сохранение и укрепление конструктивных рабочих отношений на уровне исполнителей. Особое внимание следует уделять расширению взаимодействия и форм сотрудничества, которые предполагают решение четко определенной и ограниченной военной задачи, способствуют повышению уровня взаимозависимости и позволяют избежать сложных политических дискуссий. В этих целях следует уделять больше внимания различным формам наращивания контактов между военными ведомствами, как это предусмотрено в главе IV Венского документа.

- Ротация инспекторов. Для того, чтобы положительный опыт и эффект укрепления доверия в рамках МДБ не ограничивался небольшой группой экспертов по контролю над вооружениями, следует также рассмотреть вопрос о переводе (по крайней мере, некоторых) занимающихся вопросами контроля над вооружениями офицеров на более длительные, но регулярные циклы ротации (например, от пяти до десяти лет). Для сохранения и использования их опыта и экспертных знаний такая ротация могла бы происходить, например, между структурами, осуществляющими деятельность по проверке выполнения соглашений о контроле над вооружениями и МДБ, подразделениями, занимающимися концептуальными вопросами, и отделами министерств, в компетенцию которых входят вопросы МДБ и контроля над вооружениями.

- Приглашенные и внештатные инспекторы. Еще один шаг, который можно было бы рассмотреть, - более регулярное включение офицеров из других частей вооруженных сил и представителей профильных отделов министерств обороны и иностранных дел в группы по проверке. Это способствовало бы распространению положительного эффекта и опыта МДБ среди более широкого круга специалистов-практиков на национальном уровне. Следуя примеру некоторых небольших стран, можно было бы также рассмотреть возможность создания системы внештатных сотрудников, занимающихся вопросами контроля над вооружениями. 
- Укрепление доверия на политическом и стратегическом уровнях. Поскольку причины нынешней напряженности в отношениях между Россией и Западом лежат намного глубже и не могут быть устранены с помощью современных МДБ, обеим сторонам следует предпринять более целенаправленные усилия по укреплению доверия на более высоком политическом и военном уровне. В идеале такие усилия должны быть сосредоточены на областях, представляющих общий интерес, создавать высокий уровень взаимозависимости и обеспечивать, чтобы взаимодействие происходило в условиях равного статуса. Примерами форматов, которые в значительной степени отвечают таким условиям, являются семинары высокого уровня по военным доктринам, предусмотренные Венским документом, различные соглашения о поддержании линий прямой связи, двусторонние встречи, такие как возобновленные заседания Российско-германской рабочей группы высокого уровня по вопросам политики безопасности или консультации между норвежским и российским министерствами обороны. Такие усилия следует понимать не как возврат к «бизнесу как обычно», а как начало откровенного и открытого обсуждения главных вопросов, вызывающих разногласия, и более глубоких причин напряженности в отношениях между Россией и Западом в сфере обороны и безопасности. На многостороннем уровне такие обсуждения могли бы проходить в рамках организованного на площадке ОБСЕ «структурированного диалога» по современным и перспективным вызовам и рискам для безопасности в регионе ОБСЕ или в рамках Совета Россия-НАТО.

Несмотря на возможности для повышения эффективности МДБ, не следует преувеличивать их влияние в условиях усиления политической напряженности и недоверия между государствами-участниками ОБСЕ. До тех пор, пока обе стороны не придут к согласию по основным вопросам их отношений в сфере обороны и безопасности, ни контакты и диалог между военными, ни режимы транспарентности и проверки не смогут устранить политическую и стратегическую напряженность между Россией и Западом, характеризующую нынешнюю ситуацию. Тем не менее, поддержание и укрепление уже налаженных позитивных отношений между подразделениями по контролю над вооружениями при одновременной работе над укреплением отношений доверия на более высоком политическом и военном уровне должны оставаться важной задачей для государств-участников ОБСЕ в сфере контроля над вооружениями и МДБ в Европе.

\section{Примечания}

209 Искренне благодарю двух анонимных рецензентов настоящей статьи за полезные отзывы и комментарии. 
210 Заявление делегации Российской Федерации. Специальное заседание Форума по сотрудничеству в области безопасности (834-е пленарное заседание), 9 ноября 2016. FSC.JOUR/ 840. Annex 3. C. 2. URL: https://www.osce.org/ru/fsc/282866.

211 См.: Pompeo M.R. On the Treaty on Open Skies// U.S. Department of State. 2020. 21 May. URL: https://www.state.gov/on-the-treaty-on-open-skies/.

212 См.: Koivula T. Conventional Arms Control in Europe and its Current Challenges // Arms Control in Europe: Regimes, Trends and Threats / T. Koivula, K. Simonen (eds.). - Helsinki: National Defence University, 2017. P. 120-123; Schaller B. Trust and Distrust in Defence \& Security Politics: A Multi-Level Analysis of the Defence and Security Relations between Norway, Sweden, Canada, and Russia. Doctoral thesis, UiT - The Arctic University of Norway, 17 June 2020. P. 126-128. URL: https://hdl.handle.net/10037/18383

213 Rowberry A. The Vienna Document, the Open Skies Treaty and the Ukraine crisis. // Brookings Institution. 2014. 10 April. URL: https:/www.brookings.edu/blog/up-front/2014/04/10/the-vienn a-document-the-open-skies-treaty-and-the-ukraine-crisis.

214 Schaller B. Trust and Distrust in Defence \& Security Politics. P. 175.

215 Klimke M., Kreis R., Ostermann C.F. Introduction // Trust, but Verify: The Politics of Uncertainty and the Transformation of the Cold War Order, 1969-1991 / M. Klimke, R. Kreis, C. Ostermann (eds.). - Palo Alto: Stanford University Press, 2016. P. 4.

216 См.: Borawski J. Confidence-Building Measures: Rescuing Arms Control. - The Fletcher Forum of World Affairs 1986, No 1. P. 111-131; Darilek R.E. The Theory of Confidence-Building Measures // The De-escalation of Nuclear Crises / J.E. Nation (ed.). - London: Palgrave Macmillan, 1992. P. 3-35; Rittberger V., Efinger M., Mendler. Toward an East-West Security Regime: The Case of Confidence- and Security-Building Measures // Journal of Peace Research. - 1990. - No 1. - P. 55-74; Vick A.J. Building confidence during peace and war. - Santa Monica: RAND Corporation, 1988. URL: https://www.rand.org/content/dam/rand/pubs/notes/2009/ N2698.pdf

217 Fearon J.D. Rationalist Explanations for War // International Organization. - 1995. - No 3. - P. 390-401.

218 См.: Договор об обычных вооруженных силах в Европе, 1990. Протокол об инспекциях // Официальный сайт ОБСЕ. URL: https://www.osce.org/ru/library/14091

219 См.: Венский документ 2011 года о мерах укрепления доверия и безопасности. 30 ноября 2011. Пункты 76 и 109 // Официальный сайт ОБСЕ. URL: https://www.osce.org/ru/fsc/86600.

220 Rowberry A. Op. cit.

221 Schaller B. Back to the Future? Revisiting Military Confidence-Building in Europe // Sicherheit \& Frieden. 2018. - No 3. P. 116.

222 Schmitt O. The Vienna Document and the Russian challenge to the European Security Architecture // Military Exercises: Political Messaging and Strategic Impact / B. Heuser, T. Heier, G. Lasconjarias (eds.). - Rome: NATO Defense College, 2018. P. 275-277.

223 См.: Goldblat J. Arms Control: The New Guide to Negotiations and Agreements. - London; Thousand Oaks: SAGE Publications, 2002. P. 309-310; Krass A.S. Verification and Trust in Arms Control // Journal of Peace Research. - 1985. - No 4. - P. 286; Welch Larson D. Trust and Missed Opportunities in International Relations // Political Psychology. - 1997. - No 3. - P. 706.

224 Welch Larson D. Op. cit. P. 706; Krass A.S. Op. cit. P. 287.

225 Allport G.W. The Nature of Prejudice. - Cambridge: Addison-Wesley Blackwell, 1954.

226 Allport G.W. Op. cit. P. 281.

227 Pettigrew T.F. Intergroup Contact Theory // Annual Review of Psychology. - 1998. P. 76.

228 Schaller B. Trust and Distrust in Defence \& Security Politics. 
229 Там же. Р. 168-169.

230 Там же. Р. 186.

231 Там же. Р. 169-170.

232 Там же. Р. 171.

233 Интервью автора с офицером по контролю над вооружениями, февраль 2019 г. См. Schaller B. Trust and Distrust in Defence \& Security Politics. P. 171.

234 Schaller B. Trust and Distrust in Defence \& Security Politics. P. 174.

235 Bell A., Wier A. Open Skies Treaty: A quiet legacy under threat. - Arms Control Association. 2019. January/February. URL: https://www.armscontrol.org/act/2019-01/features/open-skies-tre aty-quiet-legacy-under-threat.

236 См.: Schaller B. Trust and Distrust in Defence \& Security Politics. P. 172-173.

237 Там же. Р. 173.

238 Там же. Р. 177-178.

239 Schaller B. Strengthening the Role of the OSCE in Times of Increased Tensions and Emerging Crisis Situations: The Untapped Potential in European Arms Control. - GCSP Strategic Security Analysis, 2021. URL: https://www.gcsp.ch/publications/strengthening-role-osce-times-increased -tensions-and-emerging-crisis-situations.

240 См.: Там же.

241 Schaller B. Trust and Distrust in Defence \& Security Politics. P. 170-171.

242 См.: Венский документ 2011 года. Глава IV: Контакты.

243 Schaller B. Trust and Distrust in Defence \& Security Politics. P. 178.

244 Венский документ 2011 года о мерах укрепления доверия и безопасности. Пункт 15.7.

245 См. там же, пункт 15.8.

246 См.: О заседании Российско-германской рабочей группы высокого уровня по вопросам политики безопасности // Официальный сайт Посольства России в Федеративной Республике Германия. 2018. 13 ноября. URL: https://russische-botschaft.ru/ru/2018/11/13/ozasedanii-rossiysko-germanskoy-rab/.

247 См.: Embetsdialog i Russland. // Det Kongelige Forsvarsdepartement. 2018. 3 March. URL: https://www.regjeringen.no/no/aktuelt/embetsdialog-i-russland/id2588469/.

248 См.: О заседании Российско-германской рабочей группы высокого уровня по вопросам политики безопасности.

249 См.: The OSCE Structured Dialogue // Официальный сайт ОБСE. URL: https://www.osce.org/ structured-dialogue.

250 См.: About NRC // NATO-Russia Council. URL: https://www.nato.int/nrc-website/en/about/ind ex.html. 